\title{
Factors Influencing Timely Response to Health Care Seeking for Diarrheal Episodes Among Children Under Five by Caregivers in Rural Uganda
}

\author{
James Muhumuza ${ }^{1}$, Lorna Barungi Muhirwe ${ }^{1}$, Charles Ssentamu ${ }^{1}$, Magnus Mordu Conteh ${ }^{2}$, \\ Nicola Martina Dunne ${ }^{2}$, Rollanda Karumuna ${ }^{3}$ \\ ${ }^{1}$ Department of Health, HIV and Nutrition, World Vision, Kampala, Uganda \\ ${ }^{2}$ Global Health Programmes Strategic Partnerships and Innovation, World Vision, Dublin, Ireland \\ ${ }^{3}$ Department of Environment Management, College of Agriculture and Environmental Sciences, Makerere University, Kampala, Uganda
}

Email address:

karumunaroland@gmail.com (R. Karumuna)

To cite this article:

James Muhumuza, Lorna Barungi Muhirwe, Charles Ssentamu, Magnus Mordu Conteh, Nicola Martina Dunne, Rollanda Karumuna. Factors Influencing Timely Response to Health Care Seeking for Diarrheal Episodes Among Children Under Five by Caregivers in Rural Uganda. Science Journal of Public Health. Vol. 5, No. 3, 2017, pp. 246-253. doi: 10.11648/j.sjph.20170503.23

Received: February 12, 2017; Accepted: March 6, 2017; Published: April 13, 2017

\begin{abstract}
Timely response to health care seeking for diarrhoea episodes has a high potential to reduce child mortality rates. This study aimed to investigate the factors influencing timely response to health care seeking for diarrheal episode among children under five by caregivers. A cross-sectional research design that involved qualitative and quantitative research methods was conducted among 1,780 systematically selected households. Multiple logistic regressions were carried out to identify the factors associated with timely health care seeking behaviors among caregivers. Over 76\% (95\% CI: 72.8-78.4\%) of the caregivers sought treatment in the first 24 hours after the onset of the diarrhea episode. Caregivers who were aged 30-39 were 0.63 times less likely to seek timely treatment for diarrhea episode (adjusted odds ratio (AOR) $=0.83,95 \%$ CI: $0.34-1.99$ ) compared to caregivers who were aged 19-29 years. Female caregivers were 1.95 times more likely to seek timely treatment (adjusted odds ratio $(\mathrm{AOR})=1.95,95 \% \mathrm{CI}$ : 1.05-1.11) compared to males. Those caregivers who had no education were 0.32 times less likely to seek timely treatment (adjusted odds ratio (AOR) $=0.51,95 \% \mathrm{CI}$ : $0.69-1.09$ ) compared to caregivers that had secondary education. Caregivers who knew the signs of diarrhoea were 0.97 times more likely to seek timely treatment (adjusted odds ratio $(\mathrm{AOR})=0.97,95 \% \mathrm{CI}$ : 0.54-3.32) compared to caregivers who did not know the signs of diarrhea. Caregivers who believed that diarrhea kills were 2.41 times more likely to seek timely treatment (adjusted odds ratio (AOR) $=2.41,95 \%$ CI: 2.03-2.94) compared to caregivers who did not believe that diarrhea kills. Caregivers who stayed near the health units $(\leq 5 \mathrm{~km})$ were 0.57 times likely to seek timely health care compared to those who stayed in far places. Health care seeking within 24 hours for diarrheal episodes among children under five by caregivers was found to be high in the selected study areas. Knowledge about signs of diarrhoea, belief that diarrhoea kills, knowledge about administering ORS, fair transport cost, waiting time and distance from the health units are the factors that influence timely health seeking among children with diarrhoea. The study recommends intensification of timed and targeted counseling $(\mathrm{ttC})$ of caregivers about timely health seeking in the subsequent programming and equipping VHTs with diarrhea treatment medicines.
\end{abstract}

Keywords: Children, Diarrhea, Timely Health Care Seeking, Uganda

\section{Introduction}

Diarrheal diseases account for 1 in 9 child deaths worldwide [1]. This is about 2,195 children that die every day globally making diarrhoea the second leading cause of death among children under the age of 5 [2]. Diarrhoea is usually defined in epidemiological studies as the passage of three or more loose or watery stools per day, or more 
frequently than is normal for the individual [3]. It is usually a symptom of gastrointestinal infection, which can be caused by a variety of bacterial, viral and parasitic organisms. Infection is spread through contaminated food or drinking contaminated water or from person to person as a result of poor hygiene and sanitation $[1,2]$.

In developing countries, diarrhoea is a leading cause of illness and death among children, where an estimated 1.3 thousand million episodes and 4 million deaths occur each year in under-five years [4]. These children experience an average of 3.3 episodes each year, but in some areas the average exceeds nine episodes each year. Where episodes are frequent, young children may spend more than $15 \%$ of their days with diarrhoea [3]. About $80 \%$ of the deaths due to diarrhoea occur in the first two years of life [5]. The main cause of death from acute diarrhoea is dehydration, which results from the loss of fluids and electrolytes in the diarrhoea stools [2]. Diarrhoea is an important cause of under nutrition. This is because children eat less during diarrhoea episode and their ability to absorb nutrients is reduced, moreover, nutrient requirements are increased as a result of infection. Each episode of diarrhoea contributes to under nutrition when episodes are prolonged; their impact on growth is increased $[6,7]$.

In Sub-Saharan Africa where Uganda lies, the trends are not any different; diarrhoea equally remains one of the major public health concerns contributing to high morbidity and mortality among children less than 5 years of age [8]. Diarrhoea is responsible for $25-75 \%$ childhood morbidity and $50 \%$ childhood mortality [9]. According to UBOS, $23 \%$ of the children below five years had suffered from diarrhoea in Uganda two weeks preceding the Demographic and Health Survey [10].

One of the critical factors attributed to the current high mortality of children due to diarrhoea episodes in Uganda is poor timely health care seeking behavior of caretakers of children below five years and a range of external factors that influence caretaker timely response to diarrheal infections [10]. Appropriate healthcare-seeking practices for diarrhoea include administering a combination of oral rehydration salts (ORSs) and Zinc to the sick child [5]. Timely provision of ORS and zinc tablets has proven to be both cost-effective and efficacious as primary interventions for preventing diarrhoea mortality [11]. However, many children with diarrhoea are not treated appropriately using these interventions due to low utilization of HCIs for CDD [4].

Most caregivers do not possess correct knowledge of symptoms of illness in children which include among others not playing normally, fever for more than 24 hours, vomiting, fast breathing, blood in stool, inability to eat or drink, convulsion and drinks poorly [12]. In addition many care givers do not think that is important to consult health personnel [7]. Moreover, healthcare utilization of mothers who have children with diarrhoea is low. This is partly attributed to socio and demographic factors and a host of challenges related to distance from health facilities, costs of services, attitudes towards health care systems, cultural beliefs and waiting time among others [5].

This study set out to assess the factors influencing timely response to health care seeking for diarrheal episode among children under five by caregivers following implementation interventions by World Vision Uganda AIM Health project areas.

\section{Methods}

\subsection{Study Setting and Design}

This study was conducted in two districts (Busia in Eastern and Kabale in South Western Uganda) where World Vision Uganda AIM Health project has been implementing MNCH interventions to improve timely response to health care seeking for diarrheal episode among children under five by caregivers. A cross-sectional research design that involved qualitative and quantitative research methods was used. The quantitative methods relied on administering a structured questionnaire while the qualitative methods involved use of discussion guides and interview guides to conduct FGD and key informant interviews. The study sites Busia and Kabale both had 890 household respondents respectively making a total of 1780 respondents. In Busia the study took place in 69 Villages and in Kabale 81 Villages making a total of 150 villages. All villages were randomly selected. Household lists for each village were obtained from the VHTs. Eleven (11) households were systematically selected from each village based on the village lists provided using random tables to obtain the random start for each village.

\subsection{Study Population}

The study population included children aged below five years and the respondents were caregivers of those children.

\subsection{Selection Criteria}

Eligibility criteria

Children aged below five years and residing within the selected study areas

Exclusion criteria

(1) Caretaker not available at the time of the study (data collection)

(2) Caretaker mentally unstable and therefore unable to respond to interview.

\subsection{Outcome Measurement}

The outcome variable of this study was timely response to health care seeking for diarrheal episode among children under five by caregivers. During data collection care givers were interviewed to report the presence or absence of diarrhea by asking, Has any of your children below five years had diarrhoea in the last two weeks preceding this study?; Timely health care seeking behaviour was probed by asking caregivers "How long after the onset of diarrhoea episode did the child get treatment?. Care givers were further probed about diarrhea treatment options, knowledge about the signs 
of diarrhea, health facility factors and WASH factors. Timely health care seeking was measured if the caregiver administered any of the recommended treatment options or sought treatment at the health center within 24 hours after the onset of a diarrhea episode. Those who do not do any of the fore mentioned within 24 hours were taken to be the category of caregivers that do not seek timely treatment during a diarrhea episode.

\subsection{Explanatory Variables}

Epidemiological variables of children, mothers and parents included age, sex, place of residence, educational status of caregiver, occupation, household size, tribe, religion, number of children produced by caregiver, transport cost, knowledge on ORS, cultural beliefs and waiting time were also investigated during the study.

\subsection{Data Collection}

A total of 24 data collectors and 2 supervisors were recruited for Busia and Kabale respectively. Prior to the data collection, the data collection tools were pre-tested to check the flow of the questions, adequacy and relevance of the questions. Quantitative data was collected using Open Data Kit (ODK) while qualitative data was collected using structured guides. During data collection all the necessary quality checks were ensured. Filled questionnaires were checked by supervisors every evening after data collection before uploading the data to the servers of World Vision Uganda.

\subsection{Statistical Analysis}

Data analysis was conducted using SPSS version 21. Descriptive statistics were used to show the sociodemographic variables, timely health care seeking behaviors, knowledge factors about diarrhea, health facility factors and WASH factors. Chi-square test, t-Test and multiple logistic regressions were carried out to identify the factors associated with timely health care seeking behaviors. With $95 \%$ confidence interval $(\mathrm{CI})$, both crude and adjusted odds ratio were calculated. $\mathrm{P}<0.05$ was considered statistically significant and all tests were two-sided.

\subsection{Ethics Approval}

Ethical approval from Institutional Research Board (IRB) of Makerere University School of Public Health "Higher Degrees, Research and Ethics Committee (HDREC)" was sought with approval number 386. Care was taken to ensure that ethical guidelines are followed throughout the implementation of the study. Permission to carry out research in the selected study areas was obtained from the district health officers (DHO), sub county chiefs in the respective areas and research assistants were introduced to the local council chairpersons in the villages where the study was carried out. Informed consent was obtained from the respondents before the interviews. Confidentiality of information obtained from the study was ensured throughout data collection, entry, and analysis and reporting. No direct benefits were provided by the study to the participants in the villages in which the study was carried out.

\section{Results}

A total of 1,780 care givers of children aged less than 5 years were interviewed in the study. Of those, 916(51.5\%) of the caregivers had a child who experienced a diarrhea episode in the last two weeks preceding this study. About $82 \%$ (95\%CI: $80.1-84.6 \%$ ) of the care givers used Health centers for treating diarrhea episodes. Of those caregivers who sought treatment for their child from a health center, $76 \%(95 \%$ CI: $72.8-78.4 \%$ ) sought treatment in the first 24 hours after the onset of the diarrhea episode.

Among those who sought treatment for diarrhea episode within the first 24 hours, majority 1,139(64\%) had primary education, majority 669(37.6) were aged between 19-29 years, $1530(86 \%)$ depended on agriculture for income and $1,459(82 \%)$ were females. Most caregivers $1441(81.5 \%)$ who sought treatment for diarrhea episode within the first 24 hours knew the signs of a child with diarrhea and only $19 \%$ had knowledge about administering ORS from home. Most care givers who sought treatment for diarrhea episode within the first 24 hours stayed in households with over 6 members (Table 1).

Table 1. Socio-demographic characteristics and knowledge factors of caregivers who sought treatment for child's diarrhea episode within the 24 hours.

\begin{tabular}{|c|c|c|c|c|}
\hline \multirow[t]{2}{*}{ Variables } & \multicolumn{4}{|c|}{ Caregiver sought treatment for diarrhea episode within the first 24 hours? } \\
\hline & Yes $(\%)$ & Chi-square & No (\%) & Chi-square \\
\hline Age & & 0.13 & & 0.22 \\
\hline $14-18$ & 1.5 & & 2.3 & \\
\hline $19-29$ & 37.6 & & 32.1 & \\
\hline $30-39$ & 34.7 & & 39.6 & \\
\hline $40-49$ & 16.5 & & 17.4 & \\
\hline Above 50 & 10.5 & & 7.7 & \\
\hline Don't know & 0.3 & & 0.9 & \\
\hline Gender & & 0.02 & & 0.11 \\
\hline Male & 18.1 & & 15.2 & \\
\hline Female & 81.9 & & 84.7 & \\
\hline Tribe & & $3.22 * *$ & & 1.31 \\
\hline Mugisu & 1.5 & & 0.8 & \\
\hline Musamia & 45.0 & & 41.1 & \\
\hline
\end{tabular}




\begin{tabular}{|c|c|c|c|c|}
\hline \multirow[t]{2}{*}{ Variables } & \multicolumn{4}{|c|}{ Caregiver sought treatment for diarrhea episode within the first 24 hours? } \\
\hline & Yes $(\%)$ & Chi-square & No (\%) & Chi-square \\
\hline Mukiga & 38.4 & & 39.8 & \\
\hline Japadhola & 3.2 & & 2.3 & \\
\hline Other & 10.0 & & 13.5 & \\
\hline Level of education & & 0.01 & & 0.04 \\
\hline None & 11.5 & & 17.3 & \\
\hline Primary & 64.2 & & 67.8 & \\
\hline Secondary & 20.7 & & 14.4 & \\
\hline Tertiary & 3.5 & & 0.6 & \\
\hline Marital status & & 0.61 & & 0.09 \\
\hline Married & 72.7 & & 67.3 & \\
\hline Co-habiting & 15.7 & & 23.1 & \\
\hline Divorced & 1.4 & & 1.9 & \\
\hline Single parent & 3.4 & & 2.5 & \\
\hline Widow/widower & 6.0 & & 4.4 & \\
\hline Major Occupation & & 0.73 & & 0.03 \\
\hline 1. Agriculture & 85.9 & & 86.3 & \\
\hline 2. Formal salaries worker & 2.2 & & 1.7 & \\
\hline 3. Casual labour & 5.5 & & 6.4 & \\
\hline 4. Business owner & 4.2 & & 3.6 & \\
\hline 5. Others & 2.2 & & 2 & \\
\hline Household size & & 0.04 & & 0.06 \\
\hline Average size & 6.3 & & 6.7 & \\
\hline Knowledge about the signs of diarrhoea & & 0.03 & & 0.35 \\
\hline Yes & 81.5 & & 53.5 & \\
\hline No & 18.5 & & & \\
\hline
\end{tabular}

The most preferred option for treating diarrhea $640(36 \%)$ was use of fluids made from plain oral rehydration salts (ORS). Other options included use of water 409(23\%), Fluid made from ORS combined with Zinc (Zinkid) 373(21\%) and homemade fluids/soups/juices $356(20 \%)$. The treatment options did not significantly differ across the two regions selected for the study $(\mathrm{P}>0.05)$-Figure 1.

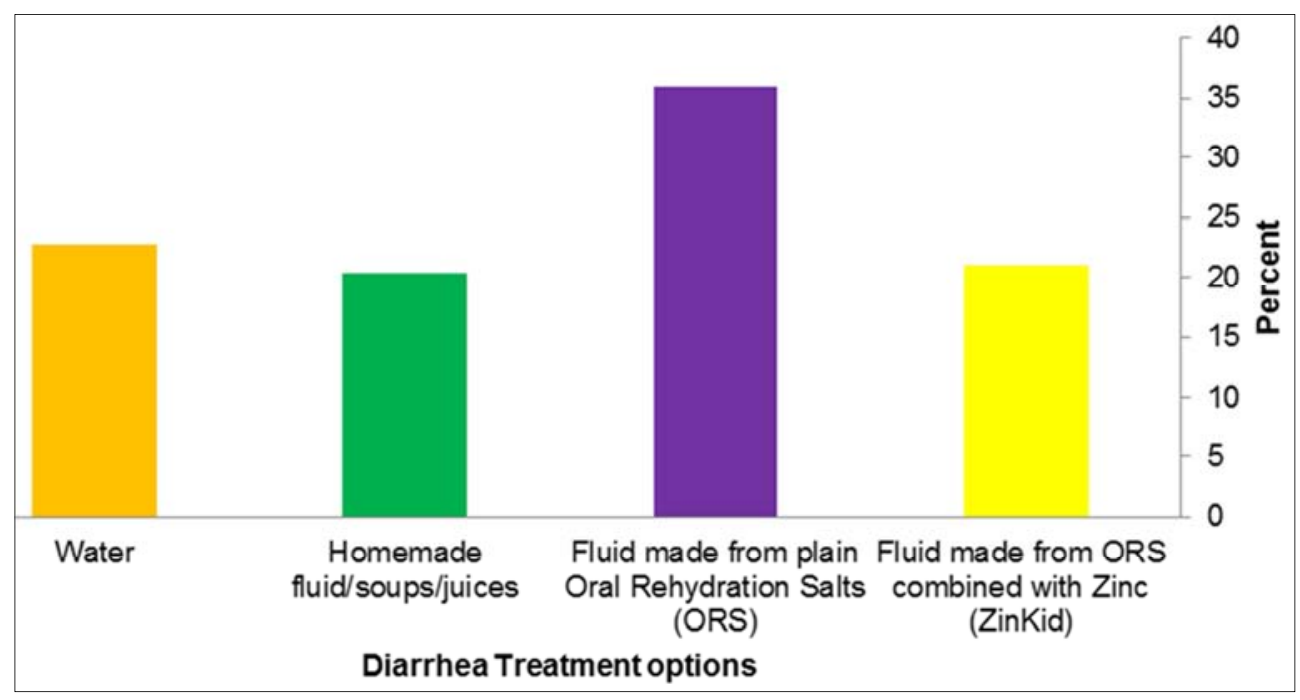

ORS: Oral Rehydration Solution

Figure 1. Diarrhea treatment options used by caregivers of children aged less than 5 years.

The most commonly reported sign of diarrhea was child not playing well 1,210(68\%). However, there were other signs reported and these included blood in the stool 284(16\%), fever for more than 24 hours 231(13\%) and three or more loose stools in a day $35(2 \%)$. The knowledge about the signs of diarrhea significantly differed between the two regions of study $(\mathrm{P}<0.05)-$ Figure 2 . 


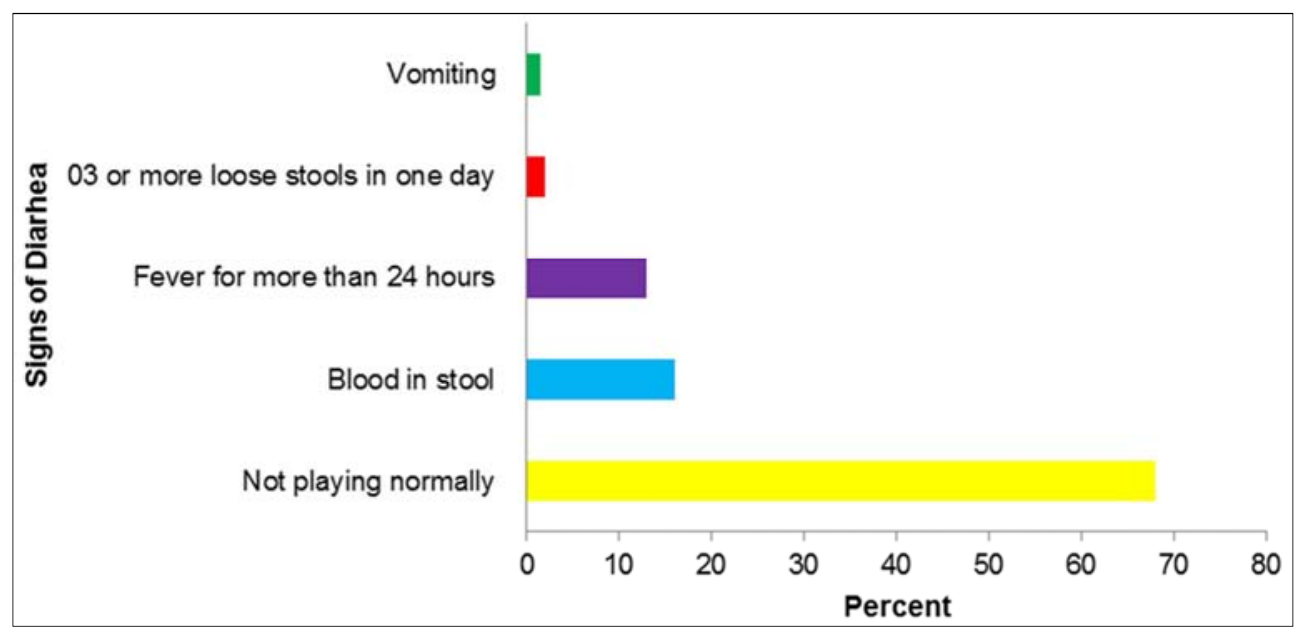

Figure 2. Knowledge about the signs of diarrhea among caregivers of children aged less than 5 years.

Most caregivers 1,477(83\%) treated childhood diarrhea at the health center. However some treated diarrhea from home $106(6 \%)$, VHT 35(2\%), traditional healer 35(2\%) and others $142(8.5 \%)$. The treatment options did not significantly differ across the two regions selected for the study.

Factors influencing caregivers' timely response to diarrheal episode

Caregivers' timely response to diarrheal episodes was associated with several factors (Table 2). Those care givers who were aged 30-39 years were 0.63 times less likely to seek timely treatment for diarrhea episode for children under five (adjusted odds ratio $(\mathrm{AOR})=0.83,95 \% \mathrm{CI}$ : $0.34-1.99$ ) compared to caregivers who were aged 19-29 years. Female caregivers were 1.95 times more likely to seek timely treatment (adjusted odds ratio $(\mathrm{AOR})=1.95$, 95\%CI: $1.05-$ 2.11). Those caregivers who had no education were 0.32 times less likely to seek timely treatment (adjusted odds ratio $(\mathrm{AOR})=0.51,95 \% \mathrm{CI}: 0.69-1.09)$ compared to caregivers that had secondary education. Caregivers who knew the signs of diarrhoea were 0.97 times more likely to seek timely treatment (adjusted odds ratio $(\mathrm{AOR})=0.97,95 \% \mathrm{CI}$ : 0.54 3.32) compared to caregivers who did not know the signs of diarrhea. Caregivers who believed that diarrhea kills were 2.41 times more likely to seek timely treatment (adjusted odds ratio $(\mathrm{AOR})=2.41,95 \% \mathrm{CI}$ : 2.03-2.94) compared to caregivers who did not believe that diarrhea kills children below the age of five years. Caregivers who perceived the cost of treating diarrhea to be cheap were 0.69 times likely to seek timely treatment of diarrhea (adjusted odds ratio (AOR) $=0.69,95 \% \mathrm{CI}$ : $0.57-0.81)$ compared to those who perceived the cost of treatment to be high. Those caregivers who believed that the health unit may have medicine were 2.31 times likely to seek timely treatment (adjusted odds ratio $(\mathrm{AOR})=2.31,95 \% \mathrm{CI}: 1.12-3.03)$ compared to those that did not believe that health centers may have medicine. Caregivers who rated the transport cost to the health unit to be fair were 0.55 times more likely to seek timely treatment (adjusted odds ratio $(\mathrm{AOR})=0.55,95 \% \mathrm{CI}$ : $0.17-0.98$ ) compared to the caregivers that rated the transport cost to the health unit to be high. Caregivers who lived near to the health units $(\leq 5 \mathrm{~km})$ were 0.57 times likely to seek timely treatment of diarrhea (adjusted odds ratio (AOR) $=0.57,95 \% \mathrm{CI}: 0.45$ 2.32) compared to caregivers who lived beyond $5 \mathrm{~km}$ from a health facility.

Table 2. Logistic regression on factors associated with caregivers' timely response to diarrheal episode.

\begin{tabular}{|c|c|c|}
\hline Variables & Crude odds ratio (95\%CI) & Adjusted odds ratio $(95 \% \mathrm{CI})$ \\
\hline \multicolumn{3}{|l|}{ Age } \\
\hline $14-18$ & 1.00 & 1.00 \\
\hline $19-29$ & $0.65(0.34-1.69)$ & $0.83(0.34-1.99) * * *$ \\
\hline $30-39$ & $1.13(0.72-1.83)$ & $1.43(0.82-1.53) *$ \\
\hline $40-49$ & $1.41(0.62-1.62)$ & $1.51(0.52-1.72) * *$ \\
\hline Above 50 & $1.26(0.42-2.32)$ & $1.37(0.72-2.62) * * *$ \\
\hline Female & $2.79(1.24-3.38)$ & $1.95(1.05-2.11)$ \\
\hline Male & 1.00 & 1.00 \\
\hline \multicolumn{3}{|c|}{ Level of education } \\
\hline None & $0.44(0.19-1.01)$ & $0.51(0.69-1.09) *$ \\
\hline Primary & $0.26(0.47-0.66)$ & $0.79(0.57-0.96) *$ \\
\hline Secondary & $0.47(0.33-0.51)$ & $0.82(0.73-1.63) * *$ \\
\hline \multicolumn{3}{|c|}{ Awareness of the signs of diarrhoea } \\
\hline Yes & $0.45(0.33-1.37)$ & $0.97(0.54-3.32)^{* * *}$ \\
\hline
\end{tabular}




\begin{tabular}{|c|c|c|}
\hline Variables & Crude odds ratio (95\%CI) & Adjusted odds ratio $(95 \% \mathrm{CI})$ \\
\hline \multicolumn{3}{|l|}{ Age } \\
\hline No & $1.05(0.73-2.37)$ & $1.59(0.46-1.86)^{*}$ \\
\hline \multicolumn{3}{|l|}{ Knowledge about signs of diarrhoea } \\
\hline Not playing normally & 1.00 & \\
\hline Blood in stool & $1.09(0.98-2.28)$ & \\
\hline Fever for more than 24 hours & $1.77(1.05-2.23)$ & \\
\hline 03 or more loose stools in one day & $0.88(0.62-1.12)$ & \\
\hline Vomiting & $1.22(1.01-1.54)$ & \\
\hline \multicolumn{3}{|l|}{ Belief that diarrhoea kills } \\
\hline No & 1.00 & 1.00 \\
\hline Yes & $3.04(2.37-3.57)$ & $2.41(2.03-2.94)^{* *}$ \\
\hline \multicolumn{3}{|c|}{ Had knowledge about administering ORS } \\
\hline Give herbs at home & 1.00 & \\
\hline ORS & $0.35(0.24-0.69)$ & \\
\hline Zinc & $0.19(0.23-0.55)$ & \\
\hline Both ORS/Zinc at home & $0.25(0.12-0.82)$ & \\
\hline Give water & $0.42(0.27-0.74)$ & \\
\hline Take child to health centre & $0.32(0.22-0.84)$ & \\
\hline \multicolumn{3}{|l|}{ Cost of treating diarrhoea } \\
\hline High & 1.00 & 1.00 \\
\hline Fair & $0.33(0.15-1.08)$ & $0.41(0.59-1.03)^{* *}$ \\
\hline Cheap & $0.46(0.57-0.55)$ & $0.69(0.57-0.81)^{*}$ \\
\hline \multicolumn{3}{|c|}{ Belief that the health unit may have medicine } \\
\hline No & $2.77(1.31-4.46)$ & $2.31(1.12-3.03)^{*}$ \\
\hline Yes & 1.00 & 1.00 \\
\hline \multicolumn{3}{|l|}{ Rating of transport cost } \\
\hline Cheap & 1.00 & 1.00 \\
\hline Fair & $0.64(0.19-1.29)$ & $0.55(0.17-0.98)^{* *}$ \\
\hline High & $0.91(0.46-1.51)$ & $0.611(0.15-1.09) *$ \\
\hline \multicolumn{3}{|l|}{ Waiting time at the Health unit } \\
\hline Less than 10 minutes & 1.00 & \\
\hline Between 11-30 minutes & $0.19(0.32-1.05)$ & \\
\hline Between 30- 01 hour & $0.72(0.22-1.34)$ & \\
\hline Hours & $1.43(0.62-2.52)$ & \\
\hline \multicolumn{3}{|l|}{ Distance from the health unit } \\
\hline$\leq 5 \mathrm{~km}$ & 1.00 & 1.00 \\
\hline $5-10 \mathrm{~km}$ & $0.61(0.62-0.92)$ & $0.31(1.09-2.12)$ \\
\hline $10 \mathrm{~km}$ and above & $0.49(0.23-1.63)$ & $0.57(0.45-2.32)^{* *}$ \\
\hline
\end{tabular}

$*<0.05, * * \mathrm{p}<0.01, * * * \mathrm{p}<0.001$

CI: Confidence Interval, km: Kilometer, ORS: Oral Rehydration Solution, $\leq$ : Equal to or less than

\section{Discussion}

Timely health care seeking by caregivers plays a major role in reducing mortality due to diarrhea episodes and the health status of children below the age of 5 years. Interestingly, $1,352(76 \%)(95 \%$ CI: $72.8-78.4 \%)$ of the caregivers sought treatment for a child within 24 hours after onset of diarrhea episodes. This health seeking behavior could be attributed to the timed, targeted counseling (ttC) program that has been under implementation by World Vision in the study areas [13]. The situation may be different in the non-intervention areas. However, this high level of health seeking by caregivers falls short of the preventive practices as $916(51.5 \%)$ of the caregivers had a child with a diarrhea episode two weeks preceding the study. This means that the prevalence of diarrhea is also still quite high. This could be attributed to the poor sanitation practices such as inconsistent hand washing especially before breast feeding children or serving them food, lack of latrine facilities, unhygienic surroundings in the houses and compounds where the children play from and use of dirty utensils to serve the children.

The finding about the time taken by caregivers to seek treatment after the onset of the diarrhea episode differs from the study finding of UNICEF and WHO conducted in developing countries. The UNICEF/WHO study found that only $40 \%$ of caregivers sought treatment within 24 hours after the on-set of a diarrhea episode [5]. However, the finding from the present study is close to the findings of other studies carried out in rural Niger (70\%), Ethiopia (54\%) and $67 \%$ in rural China $[14,15,16]$. The timely health seeking behaviors in the study areas are attributed to the World Vision program interventions, hygiene and sanitation 
campaigns and parent support group engagements. The interventions have been focused on encouraging caregivers to seek treatment within 24 hours after the onset of the diarrhea episode. However this may not have changed the cultural beliefs and practices which explains the high prevalence of the diarrhea episodes.

The present study has revealed that the older caregivers (30 years and above) were less likely to seek timely treatment compared to younger caregivers below 30 years old. This finding is consistent with the finding of Azage and Haile carried out in Ethiopia which found that caregivers aged 2534 years were $44 \%$ less likely to seek treatment from the health centers [17]. This could be attributed to the experience gained over time in treatment of childhood diarrhea. Younger caregivers are always keen to treat illnesses among children in fear of the consequences compared to older ones who may consider such illnesses to be minor [16].

Female caregivers were 23 times more likely to seek timely health care than their male counterparts. This was so because male caretakers reported to be pre-occupied with other roles such as securing the livelihoods for their families and at times are not very close with the children to monitor their health. Most male caregivers had either lost the female caregivers to death, or separated due to various factors such as violence or infidelity and were forced to care for their children. They thus often times left them at home under the care of their elder brothers or sisters and these may not report diarrhea episodes immediately as they are not knowledgeable about the signs. Aigbokhaode et al., also reported more females than males who sought health care for children under five in Edo State, Nigeria [5].

Caregivers who had not gone to school were 31 times less likely to seek timely health care compared to those that had primary education. This study has established that the lesser the education level of the caregiver the less the ability to detect certain signs of diarrhea episode as it is beginning. Secondly most uneducated caregivers had negative attitudes towards timely health care seeking because they believed in traditional approaches of treatment such as giving herbs to cure diarrhea. In addition, they did not believe that diarrhea was mainly due to poor sanitation and attributed it to some myths such as poor feeding and sleeping with the child while pregnant. These findings are consistent with the study from Morang district, Nepal which focused on mothers' beliefs and barriers about childhood diarrhea and its management [18].

Awareness about the signs of diarrhea has a positive influence on timely health seeking among the caregivers. Caregivers that could easily interpret the signs of diarrhea reported taking their children within the first 24 hours of onset of the episode. Some of the commonly reported signs were child not playing normally, blood in stool, fever for more than 24 hours and 03 or more loose stools in one day. However these signs are sometimes attributed to other illnesses other than diarrhoea [19]. Those who did not understand the signs reported that they would wait to first be sure as they would mistake this for other conditions such as teething or learning how to sit. Similar misconceptions were reported to delay health care seeking in Mkuranga District, Tanzania [3].

Caregivers who believed that diarrhea kills were 35 times more likely to seek timely health care for diarrhea compared to those caregivers that believed that diarrhea cannot kill a child. The belief that diarrhea does not kill was held by caregivers who had more than one child. These categories reported waiting for the child to recover on their own and would only seek treatment for their children if they became very ill and dehydrated. This belief is also influenced by the age of the caregiver where older caregivers were less likely to believe that diarrhea can kill a child.

The belief that the health center could have medicine for treating childhood diarrhea also had an influence on the timely health care seeking for children under five. Caretakers who believed that there are usually no medicines for treating diarrhea were less likely to seek timely treatment for their children. They looked at this as a waste of time moving all the way from home to seek treatment only to find no drugs in the government-owned health facilities. They complained of being sent to private clinics to buy the medicines which made them opt to remain home and treat diarrhea with other methods such as herbs in the event that they lacked money to buy ZinKid (ORS combined with Zinc) from private clinics. Those who had knowledge on ORS opted to use a homemade mixture and gave it to their children rather than going to the health centers. Gregorio et al., also advocated for ORS supplementation to reduce frequenting of health centers that often lack drugs [20].

Caregivers that rated the cost of transport to a health facility to be too high were 39 times less likely to seek timely health care compared to those who rated the cost to be low/ affordable. Due to high costs of transport for some caregivers, they end up not taking their children to health centers. This finding is consistent with the assessment of cost of integrated community health services for treating diarrhea [21] and health care seeking behaviors for childhood illnesses among caregivers in Nairobi slums [22].

\section{Conclusion}

Health care seeking within 24 hours for diarrheal episodes among children under five by caregivers has been found to be high in the selected study areas. This could be due to the World Vision Uganda Programs that have been under implementation in the last five years in the study areas. This shows that with effective interventions, it is possible to improve timely health care seeking for diarrheal episodes in rural areas. The factors that positively influence this timely response include knowledge about signs of diarrhoea, belief that diarrhoea kills, knowledge about administering ORS, belief that the health unit may have ZinKid, fair transport cost and lower waiting time at the health units. The current WHO recommendations are to offer zinc and ORS to children with acute diarrhoea who are 2 months to 4 years of age. Although these recommendations have been adopted by 
Uganda; barriers to timely access to treatment demonstrated in this study included distance from the health facility, long waiting times in health facilities and stock out of recommended diarrhoea management commodities. The study recommends adaption of demand creation interventions to improve timely response to health care seeking for diarrheal episodes among children under five by caregivers in rural areas, and equipping VHTs with ORS + Zinc to ease access to timely and recommended diarrhea treatment.

\section{References}

[1] C. L. F. Walker, I. Rudan, L. Liu, H. Nair, E. Theodoratou and Z. A. Bhutta, "Global burden of childhood pneumonia and diarrhoea," Lancet, Vol. 381, No. 9875, 2013, pp. 1405-1416.

[2] CDC, "Diarrhea: Common Illness, Global Killer," 2016. http://www.cdc.gov/healthywater/global/diarrhea-burden.html.

[3] R. K. Kakulu, "Diarrhoea among under five children and household water treatment and safe storage factors in Mkuranga District, Tanzania,", (MSc Dissertation). Applied Epidemiology: Muhimbili University of Health and Allied Sciences, 2012.

[4] A. Q. Aigbokhaode, E. C. Isah and A. R. Isara, "Health seeking behaviour among caregivers of under-five children in Edo State, Nigeria," SEEJPH, Vol. 10, pp. 20152014-2041.

[5] UNICEF/WHO, "Diarrhea: why children are still dying and what can be done," 2009.

http://apps.who.int/iris/bitstream/10665/44174/1/9789241598 415_eng.pdf.

[6] C. Boschi-Pinto, C. F. Lanata, W. Mendoza and D. Habte, "Diarrheal diseases". In D. Jamison, R. Feachem, M. Makgoba, E. Bos, F. Baingana, K. Hofman, et al. (Eds). "Disease and mortality in Sub- Saharan Africa," Washington, DC: World Bank, 2006; ch. 9.

[7] G. H. Tee, G. Kaur, P. Ramanathan, N. M. Amal and K. Chinna, "Health seeking behavior among Malaysians with acute diarrheal disease," Southeast Asian Journal of Tropical Medicine and Public Health, Vol. 42, No. 2, 2011, pp. 424435 .

[8] C. F. Walker, J. Perin, M. Aryee, C. Boschi-Pinto and R. Black, "Diarrhea incidence in low- and middle-income countries in 1990 and 2010: a systematic review," BMC Public Health, Vol. 12, 2012, pp. 220-233.

[9] C. Boschi-Pinto, L. Velebit and K. Shibuya, "Estimating child mortality due to diarrhoea in developing countries," Bulletin of the World Health Organization, Vol. 86, No. 9, 2008, pp. 710-717.

[10] UBOS, "Uganda Demographic and Health Survey", Uganda Bureau of Statistics and Macro International Inc Calverton, Maryland, USA; 2011.

[11] C. J. Colvin, H. J. Smith, A. Swartz, J. W. Ahs, J. Heer and N.
Opiyo, "Understanding careseeking for child illness in subSaharan Africa: a systematic review and conceptual framework based on qualitative research of household recognition and response to child diarrhoea, pneumonia and malaria," Social Science and Medicine, Vol. 86, 2013, pp. 6678.

[12] B. M. Bagbi, O. Anthonia and E. F. O. Enato, "Assessment of Care-seeking Behaviour for Under Five Years Old Children with Malaria and Other Childhood Illnesses in Some Communities in Edo State, Nigeria," Journal of Science and Practice of Pharmacy, Vol. 1, No. 1, 2014, pp. 49-58.

[13] World Vision, "Access to Infant and Maternal Health (Aim Health)" Project Endline Review Evaluation Report KampalaUganda, Final Report of First Africa, 2015.

[14] T. Assefa, T. Belachew, A. Tegegn and A. Deribew, "Mothers' health care seeking behavior for childhood illnesses in Derra District, Northshoa Zone, Oromia Regional State, Ethiopia," Ethiopian Journal of Health Sciences, Vol. 18 No. 3, 2008, pp. 87-94.

[15] A. L. Page, S. Hustache, F. J. Luquero, A. Djibo, M. L. Manzo and R. F. Grais, "Health care seeking behavior for diarrhea in children under 5 in rural Niger: results of a crosssectional survey," BMC Public Health, Vol. 11, 2011, pp. 389-397.

[16] W. Gao, S. Dang, H. Yan and D. Wang, "Care-seeking pattern for diarrhea among children under 36 months old in rural western China" PLoS ONE, Vol. 7, No. 8, 2012, e43103.

[17] M. Azage and D. Haile, "Factors affecting healthcare service utilization of mothers who had children with diarrhea in Ethiopia: evidence from a population based national survey," Journal of rural and remote health research, Vol. 15, 2015, pp. 3493-401.

[18] M. Ansari, M. I. M. Ibrahim, M. A. Hassali, P. R. Shankar, A. Koirala and N. J. Thapa, "Mothers' beliefs and barriers about childhood diarrhea and its management in Morang district, Nepal," BMC research notes, Vol. 5, 2012, 576-588.

[19] S. E. Wilson, C. T. Ouédraogo, P. Lea, A. Ouédraogo, S. Y. Hess and N. Rouamba, "Caregiver recognition of childhood diarrhea, care seeking behaviors and home treatment practices in rural Burkina Faso: A cross-sectional survey," PLOS ONE, Vol. 7, 2012, pp. 33273-33286.

[20] G. Gregorio, L. Dans, C. Cordero and C. Panelo, "Zinc supplementation reduced cost and duration of acute diarrhea in children," Journal of Clinical Epidemiology, Vol. 60, No. 6, 2007, pp. 560-566.

[21] D. Collins, Z. Jarrah, K. D. Wright and A. C. Lee, "The cost of integrated community health services for treating child pneumonia, diarrhoea, and malaria in three African countries: economic research using systematic sampling". The Lancet, Vol. 381, 2013, S31.

[22] N. Taffa and G. Chepngeno, "Determinants of health care seeking for childhood illnesses in Nairobi slums," Tropical Medicine and International Health, Vol. 10, No. 3, 2005, pp. 240-245. 